\title{
Increased double product on Monday morning during work
}

\author{
Genjiro Kimura, Nobutaka Inoue, Hiroumi Mizuno, Masaaki Izumi, Katsuyuki Nagatoya, Akira Ohtahara, \\ Masanori Munakata and Workplace Hypertension Co-operative Study by 29 Rosai Hospitals belonging to the \\ Japan Organization of Occupational Health and Safety
}

It has been reported that cardiovascular events often occur on Monday morning, especially in the young working population. Because hypertension is a major cardiovascular risk, we examined whether blood pressure was elevated on Monday, especially in the morning during work. However, there were no weekly rhythms in blood pressure itself. Instead, we found significant interactions between the double product (systolic blood pressure $\times$ heart rate) and weekly (high on Monday) and circadian (high in the morning) rhythms. Further studies are required to determine whether Monday morning preference in cardiovascular events is caused by increased double product.

Hypertension Research (2017) 40,671-674; doi:10.1038/hr.2017.16; published online 23 February 2017

Keywords: blood pressure; cardiovascular event; workplace hypertension; double product; heart rate; stress

\section{INTRODUCTION}

It has been reported that cardiovascular events ${ }^{1-7}$ and stroke ${ }^{8}$ often occur on Mondays, ${ }^{2,3,5-8}$ especially in non-hospitalized ${ }^{1}$ active working populations younger than 65 years old. ${ }^{1,3}$ In addition, these cardiovascular events are recognized mostly during the morning. ${ }^{9,10}$ Because hypertension is a major cardiovascular risk, ${ }^{11}$ we examined whether blood pressure (BP) is elevated on Monday, especially in the morning during work.

\section{METHODS}

\section{Subjects}

Day-time (full-time) active workers who were already diagnosed with essential hypertension and who worked only from Monday to Friday were recruited from 29 Rosai hospitals belonging to the Japan Organization of Occupational Health and Safety. Only subjects whose BP remained stable without changing their BP medication during the study were included. No one worked during the night or Saturday through Sunday. They had neither cardiovascular events nor arrhythmia during the previous 6 months. All participants understood the study protocol and agreed to participate in the study.

Study protocol of BP and heart rate measurements

On the first day when participants visited the hospital for the study, a serum sample was drawn for hemoglobin $A_{1} c$, total cholesterol and high-density lipoprotein cholesterol, uric acid and creatinine concentrations. The urinary excretion rates of albumin, sodium and potassium over a whole day were measured using the bag collection method within 1 week of the first visit. These biochemical parameters were all measured in the central laboratory. Workplace psychosocial stress and the degree of depression were also quantitatively evaluated using a job content questionnaire (JCQ $)^{12}$ and a self-rating depression scale. ${ }^{13-15}$

$\mathrm{BP}$ and heart rate (HR) were both measured on 3 days (Monday, Friday and Saturday or Sunday in a random order), and on each day, both the BP and HR were measured on four occasions: waking time, $1000 \mathrm{~h}, 1600 \mathrm{~h}$ and before sleeping. For the waking time measurement, BP and HR had to be measured within $1 \mathrm{~h}$ after waking up and urinating but before breakfast and taking medication. Before sleeping, BP and HR were measured at least $1 \mathrm{~h}$ after drinking alcohol and bathing. First-time measurements of BP and HR were collected for the analysis, and the measurements were completed in 207 workers (114 men and 93 women), although there were 8-12 missing values for each measurement. The study design and protocol were approved by the ethics committee of the Japan Organization of Occupational Health and Safety. ${ }^{13}$

BP and HR measurements and their recording

$\mathrm{BP}$ and HR were measured via oscillometric methods using a BP monitoring device (HEM-7251G; Omron Healthcare, Kyoto, Japan), and their values were automatically transferred to a data center by wireless telephone.

\section{Statistical analysis}

Two-way analyses of variance were performed, and the significance of the interactions between weekly and circadian rhythms was detected. Data are shown as the mean \pm s.d., and $P<0.05$ was considered significant.

\section{RESULTS}

The basic features of the study participants $(n=207)$ are shown in Table 1; the average participant was a 51-year-old active worker with controlled hypertension. The systolic and diastolic BPs as well as HR data 
on four occasions (waking time, $1000 \mathrm{~h}, 1600 \mathrm{~h}$ and before sleeping) on three different days of the week (weekend: Saturday or Sunday, working days: Monday and Friday) are summarized in Table 2. There were no

Table 1 Basic features of participants

\begin{tabular}{|c|c|c|c|}
\hline & Total & Men & Women \\
\hline Number of participants & 207 & 114 & 93 \\
\hline Age (years) & $51.2 \pm$ & $51.1 \pm 8.4$ & $51.4 \pm 8.7$ \\
\hline Height $(\mathrm{cm})$ & $164 \pm 9$ & $170 \pm 5$ & $158 \pm 6$ \\
\hline $\mathrm{BMI}\left(\mathrm{kg} \mathrm{m}^{-2}\right)$ & $24.5 \pm 3.9$ & $25.6 \pm 4.2$ & $23.2 \pm 3.1$ \\
\hline Serum uric acid (mg dl- ${ }^{-1}$ ) & $5.7 \pm 1.4$ & $6.2 \pm 1.3$ & $4.9 \pm 1.1$ \\
\hline Urinary albumin (mg day ${ }^{-1}$ ) & $16.7 \pm 56.1$ & $24.4 \pm 75.0$ & $4.5 \pm 6.4$ \\
\hline Urinary $\mathrm{NaCl}\left(\mathrm{g} \mathrm{day}^{-1}\right)$ & $12.7 \pm 12.7$ & $15 \pm 16.5$ & $9.7 \pm 2.8$ \\
\hline
\end{tabular}

Mean \pm s.d. Abbreviation: BMI, body mass index. significant interactions between systolic or diastolic BP and weekly or circadian rhythms, except for diastolic BP in women $(P<0.03)$. However, there were significant interactions between HR (total: $P<0.003$, women: $P<0.0095)$ and in the double product $(\mathrm{W}-\mathrm{P}$ or rate pressure product $=$ systolic $\mathrm{BP} \times \mathrm{HR}$ ) (total: $P<0.02$, women: $P<0.007$ ). Significant interactions between the double product and both weekly (high on Monday) and circadian (high in morning) rhythms are demonstrated in Figure 1. Post hoc analysis also showed that W-P in the morning (1000 hours) was significantly higher on Monday than on weekends in the total $(P<0.0001)$ and female $(P<0.0001)$ populations, as shown by two-way analysis of variance. However, between Monday and Friday, a significant difference was found only in the total participants $(P<0.02)$, not in men or women.

We found that the increases in $\mathrm{W}-\mathrm{P}$ on Monday morning (around 1000 hours) during work were correlated with serum uric acid (total: $P<0.03$, women: $P<0.02$ ), urinary albumin excretion rate

Table 2 Blood pressure and heart rate

\begin{tabular}{|c|c|c|c|c|c|}
\hline \multicolumn{6}{|c|}{ Systolic BP (mmHg) } \\
\hline \multicolumn{6}{|l|}{ Total } \\
\hline Monday & $134 \pm 16$ & $136 \pm 17$ & $135 \pm 18$ & $128 \pm 17$ & \multirow{2}{*}{0.8} \\
\hline Friday & $135 \pm 17$ & $136 \pm 18$ & $135 \pm 18$ & $127 \pm 18$ & \\
\hline \multicolumn{6}{|l|}{ Men } \\
\hline Friday & $137 \pm 15$ & $137 \pm 18$ & $136 \pm 16$ & $130 \pm 18$ & 0.6 \\
\hline \multicolumn{6}{|l|}{ Women } \\
\hline Holiday & $131 \pm 18$ & $128 \pm 18$ & $129 \pm 17$ & $125 \pm 17$ & \multirow[t]{3}{*}{0.15} \\
\hline Monday & $132 \pm 17$ & $135 \pm 16$ & $133 \pm 19$ & $127 \pm 18$ & \\
\hline Friday & $133 \pm 19$ & $134 \pm 19$ & $134 \pm 20$ & $124 \pm 18$ & \\
\hline Friday & $88 \pm 13$ & $87 \pm 12$ & $86 \pm 12$ & $80 \pm 13$ & 0.5 \\
\hline \multicolumn{6}{|l|}{ Men } \\
\hline Holiday & $89 \pm 12$ & $88 \pm 11$ & $87 \pm 12$ & $80 \pm 14$ & \multirow[t]{3}{*}{0.9} \\
\hline Monday & $89 \pm 11$ & $88 \pm 13$ & $88 \pm 12$ & $80 \pm 13$ & \\
\hline Friday & $89 \pm 13$ & $88 \pm 11$ & $88 \pm 11$ & $99 \pm 81$ & \\
\hline \multicolumn{6}{|l|}{ Women } \\
\hline Holiday & $85 \pm 12$ & $81 \pm 12$ & $83 \pm 13$ & $79 \pm 12$ & \multirow[t]{3}{*}{0.03} \\
\hline Monday & $85 \pm 12$ & $87 \pm 11$ & $85 \pm 13$ & $79 \pm 11$ & \\
\hline Friday & $85 \pm 13$ & $86 \pm 12$ & $85 \pm 12$ & $78 \pm 13$ & \\
\hline \multicolumn{6}{|l|}{$H R(b p m)$} \\
\hline \multicolumn{6}{|l|}{ Women } \\
\hline Holiday & $69 \pm 11$ & $71 \pm 11$ & $73 \pm 12$ & $71 \pm 11$ & \multirow[t]{3}{*}{0.009} \\
\hline Monday & $70 \pm 12$ & $78 \pm 13$ & $76 \pm 13$ & $73 \pm 11$ & \\
\hline Friday & $70 \pm 12$ & $73 \pm 12$ & $74 \pm 10$ & $73 \pm 10$ & \\
\hline
\end{tabular}




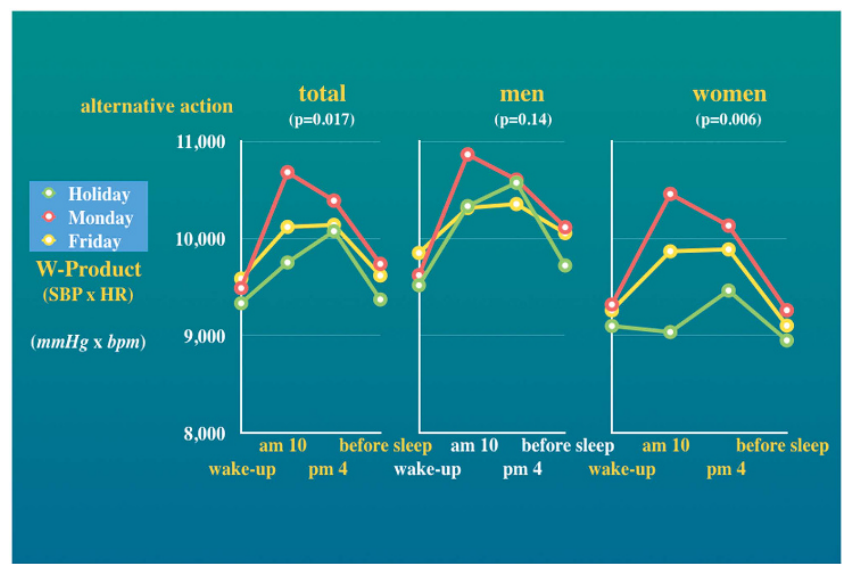

Figure 1 Double product elevation on Monday morning during work. There was a significant interaction (alternative action) between the double product (systolic $\mathrm{BP} \times$ heart rate: $\mathrm{mmHg} \times \mathrm{bpm}$ ) and weekly and circadian rhythms, especially in women and in the overall population. In the graphs, green, red and yellow represent the weekend (Saturday or Sunday), Monday and Friday, respectively. The horizontal axes on the bottom of the figures indicate the time of the day (from left to right: waking time, $10 \mathrm{am}, 4 \mathrm{pm}$ and before sleeping) for the graphs of the overall, male and female populations.

(women: $P<0.01$ ), urinary sodium/potassium ratio (women: $P=0.05$ ) and the job strain index estimated by JCQ (women: $P=0.05$ ). Multiple regression analysis indicated that serum uric acid $(P<0.02)$ and albuminuria $(P<0.03)$ were independent factors to determine elevated $\mathrm{W}-\mathrm{P}$ in women. In men, the increase in $\mathrm{W}-\mathrm{P}$ remained nonsignificant $(P=0.14)$, and none of the measured parameters correlated with the elevation in $\mathrm{W}-\mathrm{P}$.

\section{DISCUSSION}

In 207 active workers, we found significant interactions between weekly and circadian rhythms in $\mathrm{W}-\mathrm{P}$, especially in women. W-P was significantly elevated at around 1000 hours during work on Monday morning. This rise in $\mathrm{W}-\mathrm{P}$ on Monday morning was correlated with serum uric acid, the urinary albumin excretion rate, the urinary sodium/potassium ratio and job strain. Finally, by multiple regression analysis, serum uric acid and albuminuria were found to be independent factors to determine elevated $\mathrm{W}-\mathrm{P}$ in women. These data indicate that the increases in $\mathrm{W}-\mathrm{P}$ on Monday morning during work may be influenced by serum uric acid and albuminuria, although the precise mechanisms by which $\mathrm{W}-\mathrm{P}$ are elevated remain unknown.

It has been reported that cardiovascular events ${ }^{1,3,4,6,7}$ and stroke ${ }^{8}$ often occur on Monday, ${ }^{3-8}$ especially in non-hospitalized ${ }^{1}$ and active patients younger than 65 years old ${ }^{1,3}$ in the working population. ${ }^{1}$ Furthermore, myocardial infarction ${ }^{1}$ and sudden death ${ }^{1,9,16}$ are also frequently observed on Monday, ${ }^{1,9,10,16}$ especially during the morning. ${ }^{9,10}$ These reports suggest that cardiovascular events occur mostly on Monday, especially during the morning in relatively young $(<65$ years old) and active workers. Such weekly and circadian rhythms may be created by working rhythm and work-related stress.

Recently, it has become clear that stress-induced cardiomyopathy, formally called Tako-tsubo cardiomyopathy, occurs mostly on Monday, ${ }^{17-19}$ especially during the morning. ${ }^{18}$ The high level of stress induced by starting weekly and daily activities on Monday morning could play an important role, as suggested by cardiovascular events, including stroke and sudden death. One report indicated that the morning surge, an acute BP rise upon awakening, is significantly larger on Monday. ${ }^{20}$ However, in our present study, BP levels upon awakening were similar on Monday, Friday and weekends, as shown in Table 2 .

However, the present study showed that the circadian rhythm of W-P was disturbed, and W-P was elevated on Monday morning during work. Since our study is cross-sectional, the occurrence of cardiovascular events remains unknown. Therefore, longitudinal studies are required to determine whether cardiovascular events in fact occur during follow-up of the participants, especially those with elevated W-P. Recently, it has been shown that W-P is a stronger predictor of cardiovascular events than $\mathrm{BP}$ or HR itself. ${ }^{21,22}$ Considering the above discussions, psychological stress associated with work and daily life may be maximally elevated on Monday, especially in the morning during work. Therefore, it seems important to measure $\mathrm{BP}$ and HR during work to monitor W-P, which may be used as a marker of stress. Currently, it is understood that masked hypertension causes cardiovascular events similar to regular hypertension. ${ }^{23,24}$ Simultaneous BP and HR measurements during work may be recommended in the workplace not only for the prevention of cardiovascular events but also to estimate workplace-related stress. In our study, there seemed to be a difference in $\mathrm{W}-\mathrm{P}$ elevation between men and women, although the tendency was similar. Because we do not have enough data concerning the characteristics and stress of the subjects' work or their relaxation on the weekend, it is impossible to discuss the causes of these gender differences.

In conclusion, we expected that BP elevation would directly contribute to the generation of cardiovascular events that occur on Monday morning during work. However, we found that there were no weekly rhythms in BP. Instead, we found clear shifts in W-P for both weekly (high on Monday) and circadian (high in the morning) rhythms. It is important to improve our understanding of the importance of $\mathrm{W}-\mathrm{P}$ in the future.

\section{WORKPLACE HYPERTENSION CO-OPERATIVE STUDY BY 29 ROSAI HOSPITALS BELONGING TO THE JAPAN ORGANIZATION OF OCCUPATIONAL HEALTH AND SAFETY}

Takano H (Hokkaido), Sameshima M (Kushiro), Sakihara T (Aomori), Sasaki T (Akita), Munakata M, Konno S (Tohoku), Yoshinari K (Fukushima), Okubo S (Kashima), Yamanouchi M (Chiba), Kondo T (Kanto), Omura M, Sugisawa C (Yokohama), Sasagawa T, Sato N (Niigata), Kinuno H (Toyama), Shinoda E, Makino Y (Hamamatsu), Uetani T, Kato M (Tyubu), Mizuno H (Asahi), Nagatoya K (Osaka), Izumi M (Kansai), Inoue N (Kobe), Hayashi Y (Wakayama), Ohtahara A (Sanin), Nanba S (Okayama), Hondo T (Tyugoku), Seki K (Yamaguchi), Satoh A (Ehime), Iwata Y (Kagawa), Kuroda T, Takatsu (Kyusyu), Yamasa T (Nagasaki) and Matsumura T (Kumamoto).

\section{CONFLICT OF INTEREST}

The authors declare no conflict of interest.

1 Willich SN, Lowel H, Lewis M, Hormann A, Arntz HR, Keil U. Weekly variation of acute myocardial infarction. Increased Monday risk in the working population. Circulation 1994: 90: 87-93.

2 Nicolau GY, Haus E, Popescu M, Sackett-Lundeen L, Petrescu E. Circadian, weekly, and seasonal variations in cardiac mortality, blood pressure, and catecholamine excretion. Chronobiol Int 1991; 8: 149-159. 
3 Witte DR, Grobbee DE, Bots ML, Hoes AW. Excess cardiac mortality on Monday: the importance of gender, age and hospitalisation. Eur J Epidemiol 2005; 20: 395-399.

4 Witte DR, Grobbee DE, Bots ML, Hoes AW. A meta-analysis of excess cardiac mortality on Monday. Eur J Epidemiol 2005; 20: 401-406.

5 Manfredini R, Fabbian F, Pala M, Tiseo R, De Giorgi A, Manfredini F, Malagoni AM, Signani F, Andreati C, Boari B, Salmi R, Imberti D, Gallerani M. Seasonal and weekly patterns of occurrence of acute cardiovascular diseases: does a gender difference exist? J Womens Health (Larchmt) 2011; 20: 1663-1668.

6 Barnett AG, Dobson AJ. Excess in cardiovascular events on Mondays: a meta-analysis and prospective study. J Epidemiol Community Health 2005; 59: 109-114.

7 Capodaglio G, Gallerani M, Fedeli U, Manfredini R. Contemporary burden of excess cardiovascular mortality on Monday. A retrospective study in the Veneto region of Italy. Int J Cardiol 2016; 214: 307-309.

8 Shigematsu K, Watanabe Y, Nakano H, Kyoto Stroke Registry C. Weekly variations of stroke occurrence: an observational cohort study based on the Kyoto Stroke Registry, Japan. BMJ Open 2015; 5: e006294.

9 Warren JV. Monday morning sudden death. Trans Am Clin Climatol Assoc 1988; 99: 10-16.

10 Gnecchi-Ruscone T, Piccaluga E, Guzzetti S, Contini M, Montano N, Nicolis E. Morning and Monday: critical periods for the onset of acute myocardial infarction. The GISSI 2 Study experience. Eur Heart J 1994; 15: 882-887.

11 Ezzati M, Lopez AD, Rodgers A, Vander Hoorn S, Murray CJ, Comparative Risk Assessment Collaborating G. Selected major risk factors and global and regional burden of disease. Lancet 2002; 360: 1347-1360.

12 Karasek R, Baker D, Marxer F, Ahlbom A, Theorell T. Job decision latitude, job demands, and cardiovascular disease: a prospective study of Swedish men. Am J Public Health 1981; 71: 694-705.

13 Inoue N, Munakata M, Ohtahara A, Izumi M, Yamauchi A, Nagatoya K, Mizuno H, Kimura G. Rosai hospital multicenter clinical investigation on Job stress-induced hypertension. JJOMT 2015; 63: 36-50.

14 Inoue N, Otsui K, Yoshioka T, Suzuki A, Ozawa T, Iwata S, Takei A. A simultaneous evaluation of occupational stress and depression in patients with lifestyle-related diseases. Intern Med 2016; 55: 1071-1075.

15 Mokarami H, Stallones L, Nazifi M, Taghavi SM. The role of psychosocial and physical work-related factors on the health-related quality of life of Iranian industrial workers. Work 2016; 55: 441-452.

16 Arntz HR, Willich SN, Schreiber C, Bruggemann T, Stern R, Schultheiss HP. Diurnal, weekly and seasonal variation of sudden death. Population-based analysis of 24061 consecutive cases. Eur Heart J 2000; 21: 315-320.

17 Manfredini R, Citro R, Previtali M, Vriz O, Ciampi Q, Pascotto M, Tagliamonte E, Provenza G, Manfredini F, Bossone E, Takotsubo Italian Network Investigators. Monday preference in onset of takotsubo cardiomyopathy. Am J Emerg Med 2010; 28: 715-719.

18 Song BG, Oh JH, Kim HJ, Kim SH, Chung SM, Lee M, Kang GH, Park YH, Chun WJ. Chronobiological variation in the occurrence of Tako-tsubo cardiomyopathy: experiences of two tertiary cardiovascular centers. Heart Lung 2013; 42: 40-47.

19 Manfredini R, Manfredini F, Fabbian F, Salmi R, Gallerani M, Bossone E, Deshmukh AJ. Chronobiology of Takotsubo syndrome and myocardial infarction: analogies and differences. Heart Fail Clin 2016; 12: 531-542.

20 Murakami S, Otsuka K, Kubo Y, Shinagawa M, Yamanaka T, Ohkawa S, Kitaura Y. Repeated ambulatory monitoring reveals a Monday morning surge in blood pressure in a community-dwelling population. Am J Hypertens 2004; 17 (Pt 1): 1179-1183.

21 Inoue R, Ohkubo T, Kikuya M, Metoki H, Asayama K, Kanno A, Obara T, Hirose T, Hara A, Hoshi H, Totsune K, Satoh H, Kondo Y, Imai Y. Predictive value for mortality of the double product at rest obtained by home blood pressure measurement: the Ohasama study. Am J Hypertens 2012; 25: 568-575.

22 Villella M, Villella A, Barlera S, Franzosi MG, Maggioni AP. Prognostic significance of double product and inadequate double product response to maximal symptom-limited exercise stress testing after myocardial infarction in 6296 patients treated with thrombolytic agents. GISSI-2 Investigators. Grupo Italiano per lo Studio della Sopravvivenza nell-Infarto Miocardico. Am Heart J 1999; 137: 443-452.

23 Lima NK, Moriguti JC, Ferriolli E. Uncontrolled hypertension in older patients: markers and associated factors to masked and white-coat effect. J Geriatr Cardiol 2016; 13: 672-678.

24 Franklin SS, O'Brien E, Staessen JA. Masked hypertension: understanding its complexity. Eur Heart J 2016 (in press).

(c) (i) (2) (2) This work is licensed under a Creative Commons Attribution-NonCommercial-ShareAlike 4.0 International License. The images or other third party material in this article are included in the article's Creative Commons license, unless indicated otherwise in the credit line; if the material is not included under the Creative Commons license, users will need to obtain permission from the license holder to reproduce the material. To view a copy of this license, visit http://creativecommons.org/licenses/bync-sa/4.0/

(C) The Author(s) 2017 